\title{
Ditos e não escritos sobre o mal-estar docente: a potência do ler e do escrever em ateliês de escrileituras
}

Spoken and unwritten notes on the teacher burnout: the potency of reading and writing in writreading workshops

Carla Gonçalves Rodrigues ${ }^{1}$ Josimara Wikboldt Schwantz ${ }^{2}$ Universidade Federal de Pelotas

\section{Resumo}

Trata-se de uma investigação qualitativa, que interroga sobre as causas e consequências do mal-estar docente na rede estadual de ensino de uma cidade do interior Sul do RS. Primeiramente, buscou por elementos sobre a temática através do exame bibliográfico na área da Saúde - mais especificamente da Psicologia - e na área da Educação. O segundo movimento visou fomentar os estudos relativos à metodologia cartográfica. Para a produção de dados, realizou pesquisa documental, utilizou entrevistas semiestruturadas e propôs atividades intervencionistas a partir de ateliês de escrileituras. Focaliza a escrita como exercício clínico, desde a Psicologia Institucional e a Filosofia da Diferença. Alguns resultados indicam a existência de uma cultura educacional de fuga do trabalho, borrando o que se denomina mal-estar docente. Entretanto, há causas e consequências apontadas que corroboram os achados de pesquisas anteriores.

Palavras-chave: Educação. Escrileituras. Cartografia.

\section{Abstract}

This is a qualitative research which questions about the causes and consequences of the teacher's burnout in state schools in a south countryside city of Rio Grande/RS. Firstly, it searched for elements on the theme by a bibliographic analysis in the field of healthcare - more specifically in Psychology - and in Education. The second movement aimed to encourage studies relating to the cartographic methodology. For data production, it conducted documentary research, used semi-structured interviews and proposed interventionist activities from writreading workshops. It focuses on writing as clinical practice, from the point-of-view of Institutional Psychology and Philosophy of Difference. Some results indicate the existence of an educational culture of escape from work, blurring what is called teacher burnout. However, there are the mentioning of causes and consequences which corroborate the findings of previous studies.

Keywords: Writreadings, Education, Cartography. 


\section{Introdução: notas sobre a investigação da docência contemporânea em mal- estar}

Este artigo é portador de um esforço que articula e tenta produzir um pensamento teórico-metodológico que faça frente às estruturas de controle e aos regimes de assujeitamento. Com isso, possibilita emergir estratégias de resistência e de criação no que tange às narrativas afirmativas do estado doentio em que se encontram os professores nos dias de hoje. Trata-se, portanto, da problematização e análise do fenômeno dito mal-estar docente (ESTEVE, 1999). Para tal, ocupa-se da rede de ensino estadual em uma cidade do interior Sul do RS, mantendo como foco os professores pertencentes a tal âmbito educacional.

É fato, o absenteísmo trabalhista e o abandono da profissão docente tornam-se latentes nos dias de hoje. A retirada do trabalho, cada vez mais, vem sendo justificada como maneira de aliviar tensões acumuladas. Nesse sentido, alguns professores recorrem frequentemente aos pedidos de licença ou as ausências por pequenos períodos, configurando solicitações oficiais de afastamento. A maior incidência desses casos é observada no início do ano letivo - em função dos padrões organizacionais da escola - e nos períodos de avaliação, regredindo nas férias e, por vezes, culminando na desistência do exercício da profissão.

Para compor a fundamentação teórica desta investigação, três movimentos conceituais foram operacionalizados. O movimento inicial baseou-se na busca por elementos sobre o mal-estar docente, por intermédio do exame bibliográfico ${ }^{1}$ na área da Saúde, mais especificamente da Psicologia, e na área da Educação. Na continuidade, ateve-se à abordagem do método investigativo qualitativo cartográfico e, por fim, à seleção de contribuições da Psicologia Institucional de Félix Guattari, bem como das Filosofias da Diferença, de Gilles Deleuze, no que tange à escrita como exercício clínico.

O livro intitulado $O$ mal-estar docente (ESTEVE, 1999) também foi fonte relevante para os estudos sobre o adoecimento dos professores. O autor, ao estudar o fenômeno no contexto espanhol, coletou dados consultando o arquivo de licenças da inspeção médica da delegacia regional da Consejería de Educación de La junta de Andalucía. Esteve (1999) ressalta que 75\% dos professores em tratamento médico têm diagnóstico referente às doenças psicológicas e mentais do tipo estados neuróticos e depressivos. Ele classifica como secundários (ou contextuais) os fatores que causam tal mal-estar, relacionando-os às condições ambientais, ao contexto em que se exerce a docência e

\footnotetext{
${ }^{1}$ Foi realizada uma consulta à base de dados SCIELO com o conjunto de palavras mal-estar docente, obtendose sete artigos. Na sequência, efetuou-se o acesso ao banco de dados Bireme, que proporcionou a captura de dois textos sobre a temática em questão. Por último, na busca realizada no PubMed, não foram encontrados artigos abordando o assunto.
} 
àqueles que incidem diretamente sobre a ação do professor em sala de aula, gerando tensões associadas a sentimentos e emoções negativas, como primários (ou principais). De maneira geral, realizando busca livre na internet, o segundo movimento proporcionou o encontro com dois textos considerados promissores naquilo que demonstram sobre metodologia da pesquisa de campo para o estudo da subjetividade. O artigo denominado A cartografia e a relação pesquisa e vida (ROMAGNOLI, 2009) e Pesquisa-intervenção e cartografia: melindres e meandros metodológicos - carrega como autoras Paulon e Romagnoli (2010).

Ambos os artigos dedicam-se à apresentação de variados métodos de pesquisa em Psicologia, atendo-se às suas suscetibilidades e sinuosidades, mais especificamente àquelas baseadas no paradigma moderno, que adotam como alicerces a razão, a objetividade e a busca da verdade. Mas não param por aí. Discutem a complexidade e os impasses atuais da Psicologia, convocando a necessidade de novos métodos, dentre eles a cartografia, como uma tentativa de lidar com a complexidade impregnada nesta atualidade. Nessa perspectiva, convocam a invenção e a implicação do pesquisador, religando a pesquisa com a vida.

Também dois livros foram selecionados para compor a fundamentação teórica sobre o uso da cartografia como método investigativo na pesquisa em Psicologia. Pistas do método da cartografia. Pesquisa-intervenção e produção de subjetividade tem Passos, Kastrup e Escóssia (2009) como organizadores do compêndio. De modo convergente, os artigos afinam com o pensamento de Gilles Deleuze e Félix Guattari, revelando inquietações relativas à metodologia de pesquisa dos dias atuais, sem deixar de lado a implicação dos autores em experimentações do pensamento ancoradas no real e no concreto de uma existência.

As psicólogas Fonseca e Kirst (2003) oferecem o livro Cartografias e devires. A construção do presente como a segunda ancoragem teórica para este trabalho. Aí há um eixo-inquietante que atravessa todos os textos, constituído pelo compromisso éticopolítico do pesquisador, não contente com as verdades postas à espera de descrições. As autoras põem a funcionar o método cartográfico, conhecendo o que nas formas pulsa como informe, vibra como força de constituição, assim como transformação.

O terceiro e último movimento, que reúne elementos capazes de dar consistência à referida pesquisa, visa ampliar a compreensão da clínica como um lugar em que vão os doentes para receberem tratamento. Mais especificamente, atentam ao que diz respeito aos atuais limites do modelo de clínica como prática individual de consultório em contraposição às práticas de uma clínica social enquanto trabalho ético e político baseado na intervenção com fins de promoção da saúde.

Revista Digital do LAV - Santa Maria - vol. 9, n. 2, p. 28 - 44. - mai./ago. 2016 ISSN 1983 - 7348 


\section{Pistas metodológicas}

\section{Plano da experiência}

Trata-se de uma investigação qualitativa do tipo intervencionista, com abordagem cartográfica, ocupada da constituição de saberes e fazeres relativos ao mal-estar docente. Impõe-se a adequação entre a natureza do problema investigado e as exigências do método escolhido, menos apreendendo estruturas e estados de coisas. Para tal, com Rolnik, entende-se a cartografia

[...] não a visão dos fatos, estes mais do que passados e repassados. Mas a audição das intensidades, a vibração dos fluxos: no corpo. Registro daquilo que se passou no invisível - o que não é feito de imagens, que não pode ter testemunha ocular e que nem por isso é menos presente e violento do que o que se passou no visível (ROLNIK, 1989, p.285).

Assim, é possível afirmar que a pesquisa cartográfica consiste no acompanhamento de processos inventivos e de produção de subjetividades, afastada da representação de objetos, pois, quando o cartógrafo entra no lócus empírico, há processos em curso. Nessa perspectiva, a investigação requer que o pesquisador habite um novo território, anteriormente pouco ou nada conhecido, cultivando uma disponibilidade à experiência. Em outras palavras, o trabalho cartográfico não visa à submissão ou domínio do lugar pesquisado, mas um fazer com, compondo os elementos do fenômeno estudado.

Como ação intervencionista, a investigação operou por meio de Ateliês oferecidos aos professores da rede de ensino referida, visando ativar o pensamento, a percepção, a criação e a comunicação. Em seus procedimentos de leitura e de escrita, implicam o campo do vivido, das sensações e das invenções. Os atos de ler e de escrever são tomados como ações criadoras de sentidos diferentes para cada leitor-escritor, em seus processos de subjetivação, bem como exercem importantes funções sociais, culturais, comunitárias, éticas e políticas.

Uma aposta nos Ateliês de Escrileituras (escrita-pela-leitura e leitura-pela-escritura) pelo fato de tratar, sempre, de alguma escritura; ou seja, de uma escrita singular, promovida por um escritor-leitor ou leitor-escritor (BARTHES, 2004). Portanto, trata-se de uma escrileitura que é autoral e que não é possível imitar, pois não pode funcionar como modelo de leitura ou método de escrita, visto que estas são avaliadas por sua capacidade de traduzir acontecimentos, capaz de produzir efeitos artistadores, transformar forças em

Revista Digital do LAV - Santa Maria - vol. 9, n. 2, p. 28- 44. - mai./ago. 2016 ISSN 1983 - 7348 
novas maneiras de sentir e de ser. Isto é, engendrar diferentes práticas de educar e revolucionárias formas de existência (CORAZZA, 2011).

\section{Produção de dados}

Quanto à produção de dados, é possível dizer que, inicialmente, realizou-se uma revisão documental no Posto de Saúde e no Núcleo Municipal de Educação Permanente em Saúde (NEPES) da cidade pesquisada e no Centro dos Professores do Estado do Rio Grande do Sul.

Tabela 01 - Número de professores afastados das atividades docentes por licença médica durante os anos de 2010 e 2011 na cidade pesquisada

\begin{tabular}{|c|c|c|}
\hline & 2010 & 2011 \\
\hline Posto de Saúde & $\begin{array}{l}\text { Total de } 677 \text { atestados emitidos; } \\
609 \text { de docentes }\end{array}$ & $\begin{array}{l}\text { Total de } 665 \text { atestados emitidos; } \\
598 \text { de docentes }\end{array}$ \\
\hline NEPES & 60 docentes & 76 docentes \\
\hline \multicolumn{3}{|c|}{$\begin{array}{c}\text { Dados extraídos de informativo estadual (MÜLLER, 2012) produzido pelo próprio órgão e } \\
\text { colaboradores }\end{array}$} \\
\hline CPERS & & $\begin{array}{c}\text { Total } 3.166 \text { docentes } \\
\text { ( } 1.578 \text { com transtorno mental) }\end{array}$ \\
\hline
\end{tabular}

Fonte: Autores.

Com tais dados, apresentados conforme a Tabela 01, afirmaram-se o interesse e a relevância de problematizar a temática, passando a escolher uma Escola para a continuidade da investigação, definindo os professores da EJA (noturno) como sujeitos. Dos 26 professores da Escola participante dessa investigação, 23 responderam a um questionário padrão², o qual informa sobre a relação entre esses afastamentos e a prática pedagógica. Como resultado obteve-se: $43 \%$ apresentaram a possibilidade de desenvolver Burnout, $31 \%$ estariam em fase inicial do adoecimento, enquanto, em $26 \%$ do grupo, o fenômeno estaria começando a se instalar.

A partir de então, planejou-se, executou-se e, em um diário de notas, registrou-se o trabalho intervencionista com os Ateliês ${ }^{3}$, bem como, posteriormente, efetuou-se entrevista com três professores que participaram da ação. Denominou-se Encontro escrilendo uma vida - Máquina de guerra para uma existência contemporânea dividido em dois momentos de quatro horas cada, realizado na Escola com os professores da EJA

\footnotetext{
${ }^{2}$ Questionário preliminar de identificação de burnout elaborado e adaptado por Chafic Jbeili, inspirado no Maslach Burnout Inventory - MBI.

3 A pesquisa com Ateliês de Escrileituras é um projeto financiado pela CAPES do Programa Observatório da Educação, coordenado pela professora Sandra Mara Corazza. Reúne a UFRGS, UFMT, UFPel e UNIOSTE-Toledo.
} 
(noturno), sujeitos desta pesquisa. O primeiro deles denomina-se Ateliê Conatus e, o segundo, Rabiscos de sensações de um corpo crianceiro.

Sobre o Ateliê Conatus, é possível contar que, primeiramente, foi lido coletivamente o texto A Metamorfose de Kafka, adaptado por Peter Kuper, em HQ. Na sequência, realizase estudo dos conceitos corpo, alma, conatus e potência de vida em Spinoza e Nietzsche, utilizando programas do Café Filosófico: A existência como doença com Márcia Tiburi e a A alegria e o trágico em Nietzsche com Roberto Machado. Compõe o conjunto a apresentação de um trecho do filme Quando Nietzsche chorou, demonstrando a ideia de Eterno retorno.

Com isso, obtém-se um conjunto filosófico-artístico a fim de criar procedimentos para interferir na linguagem, no esburacamento com forças ativas de uma vida docente, dita adoecida pelos recursos da pesquisa científica. A oferta desses materiais foi intercalada com exercícios livres de escrileituras, culminando na reunião das escrituras em três grupos para a criação de personagens e, posteriormente, de um podcast - pequenas novelas para rádio.

Rabiscos de sensações de um corpo crianceiro caracterizou-se por proporcionar aos participantes vivencias infantis. O grupo participante experimentou circuitos compostos por subsídios filosóficos e artísticos (literatura), intercalados por elementos do universo crianceiro. Por se tratar de atividades que exigem disposição corpórea, foi proposto um aquecimento físico de alongamento. Em seguida, passou-se ao exercício de Blablação, no qual os professores conversavam consigo, experimentando outras formações de palavras, quase como balbucios, criando uma linguagem própria e explorando-a. Andando pela sala, juntaram-se com um colega, seguindo a conversa na linguagem inventada, podendo unir-se em grupos para continuar este "bate papo".

Após a blablação, realizaram-se brincadeiras, tais como Batatinha 1,2,3..., Estátua e Escravos de Jó. Na sequência, foi realizada breve apresentação da biografia de Manoel de Barros e do vídeo Histórias da unha do dedão do pé do fim do mundo. Também se realizou a projeção e leitura do livro Discurso do urso de Cortázar (2009). Ainda, utilizaram-se partes do documentário Só Dez Por Cento é Mentira, de Manoel de Barros. Disponibilizou-se uma caixa com frases retiradas de obras de Manoel de Barros. Executou-se a leitura oralmente, com o objetivo de fomentar o exercício de escriler.

Fragmentos do vídeo Abecedário de Gilles Deleuze (2001) foram apresentados, focalizando o conceito filosófico de devir criança. Também se utilizou o vídeo educativo denominado Pensamento infantil, elaborado pela publicação Nova Escola para cultura de massa. Para estabelecer conversação sobre o vivido durante o Ateliê, fizeram-se as seguintes questões: Quais relações são possíveis de estabelecer entre os dispositivos 
utilizados neste Ateliê, a vida professoral e a composição de escrileituras? Por fim, os participantes montaram um livro, reunindo as folhas $A 2$ recebidas no início do Ateliê. No que tange às entrevistas realizadas com os três professores, é possível dizer da sua receptividade, oferecendo variados e relevantes dados para pensar sobre o mal-estar docente. Todas as entrevistas foram feitas no mesmo dia, na cidade pesquisada, tendo cada uma, tempo variável de 40 a 50 minutos. Utilizou-se de questionário semiestruturado contemplando tanto os dados de identificação dos entrevistados, bem como questões conceituais, de causa, consequência e verificadoras de hipótese sobre o fenômeno estudado.

Quanto à caracterização dos sujeitos entrevistados, revela-se que uma das docentes, aqui denominada Professora A, é formada há 29 anos em Educação Física, tem 46 anos, é casada e possui uma filha menor de idade. Atualmente, trabalha na rede pública de ensino municipal e estadual, atua tanto no Laboratório de Informática como em aulas de Educação Física. A isso agrega um contrato temporário em uma determinada Universidade, totalizando jornada semanal de 80 horas. Possui Mestrado em Enfermagem e Saúde, Especialização em Atividade Física Personalizada e Especialização em Metodologia de Ensino.

Com 39 anos, casado, uma filha menor de idade, o Professor, que aqui será denominado B, é formado há 17 anos em História (licenciatura e bacharelado), possui Especialização em Educação Brasileira. Por ora, cursa Mestrado profissional em História. Trabalha em duas escolas municipais com 40 horas semanais, tendo 13 anos de serviço. A Professora C está com 49 anos, é solteira e possui uma filha. Está formada há 30 anos em Estudos Sociais, atua como Diretora de Escola na única instituição em que atualmente trabalha por 40 horas. É especialista em Supervisão Escolar.

\section{Saberes que emergem do fazer}

\section{A caixa preta do mal-estar docente: Estão os professores adoecidos?}

O processo investigativo favoreceu compreensão um tanto mais ampliada do binômio saúde-doença, afastando-se da ênfase no corpo adoentado e diluindo fronteiras entre enfermos e saudáveis. Não há maiores dúvidas de que algumas questões-respostas, oferecidas pela Professora A, foram determinantes para tal deslocamento. Durante a entrevista, ela fortemente indaga sobre quem diz que há um mal-estar docente?. E se mantém interrogando: São os professores que dizem que há um mal estar docente? Não sei, eu penso que isso tem que ser questionado. [...] todas as funções, todos os cargos que lidam com pessoas hoje, então, sofrem de mal estar?.

Revista Digital do LAV - Santa Maria - vol. 9, n. 2, p. 28 - 44. - mai./ago. 2016 ISSN 1983 - 7348 
Sendo assim, segue-se adiante desconfiando da existência de alguma trama de charadas na lógica que anima o mal-estar professoral. Ao considerar que a referida professora trabalha 80 horas semanais e que ela admite que a categoria enfrenta certa desvalorização profissional, expressa tanto socialmente como nos baixos salários, poderse-ia aqui, com Esteve (1999), sustentar a ideia da existência do adoecimento docente. Entretanto, a Professora A não faz menção aos fatores secundários ou primários que configuram tal mal-estar, de acordo com o autor, relacionados às condições ambientais em que se exerce a docência e àqueles que incidem diretamente sobre a ação do professor em sala de aula, respectivamente.

Ao contrário do que se vinha pensando, ela afirma que aquilo que é dito como adoecimento pode não ser adoecer, pode ser uma fuga, uma estratégia. Explicando melhor: Essa professora com 80 horas semanais de atividades pode querer durante uma semana afastar-se do trabalho porque eu preciso fazer outra coisa que naquele momento me interessa mais. Então, esse adoecer é questionável.

Durante a entrevista, a Professora A ofereceu a compreensão de que o fenômeno pesquisado é um hábito da cultura escolar,

uma cultura que não representa um adoecimento físico. Para isso eu uso as minhas faltas, eu uso os meus atestados, eu posso simplesmente ir fazer compras. Eu posso ir fazer uma limpeza de pele (risos). Eu acho que os números de atestados não necessariamente representam o mal-estar docente.

Em contrapartida, o professor B apresenta respostas que - referendadas pela Professora C - corroboram os estudos de Esteve (1999) tanto sobre os indicadores de mal-estar docente, como no que diz respeito às consequências por ele geradas. Tais respostas também afirmam alguns dados exibidos pelo CPERS.

Esse mal-estar é de difícil compreensão, porque é um problema extremamente complexo. Em linhas gerais é um mal-estar físico e psicológico. Os professores em geral estão fatigados, com poucas horas de sono, cansados fisicamente. Também com problemas de doenças físicas e, problemas de doença na garganta. Hoje o professor é um profissional desrespeitado profissionalmente, desvalorizado economicamente e isso acaba evidentemente tendo consequências sérias na sua personalidade e na sua própria vida pessoal.

Atualmente, considera-se falido o projeto de apropriação de uma dada identidade totalitária. De acordo com Bauman (2003), tende-se a redefinir qual o propósito de uma vida, considerando fortemente suas singularidades, considerando o que está acontecendo 
com o sujeito dessa vida, no aqui e agora. Cada indivíduo cria sua própria identidade, não mais se a herda ou incorpora, pois, em função da diversidade dos modos de vida existentes, acaba-se por passar o tempo todo definindo o que serve ou não serve para a própria existência.

É fato: As instituições educacionais perderam grande parte do seu poder de governamentabilidade e da sua função disciplinadora, conforme talhado por Foucault (2008). Entretanto, quem é amputado, melhor dizendo, quem acaba sendo nomeado e colocado na posição de doente, especialmente mental - conforme os dados da pesquisa do CPERS e levantamento realizado no NEPES - o professor é nomeado como despreparado, ineficiente, desinteressado e apático, culminando em desprestígio pela categoria diante do fracasso do antigo projeto educacional civilizatório, assim como acentuando o sentimento de culpa.

Tomando outra direção, a Professora C - gestora escolar - afirma que as licenças dos professores do trabalho escolar, concedidas por profissionais da saúde, são uma busca legal e uma fuga. Por um lado, explica a "busca legal" como sendo os atestados fornecidos pelos médicos, assim como os laudos, isto é, afastamento por doenças causadas, normalmente um ferimento, um acidente. Também aborda os afastamentos concedidos por psicólogas: é difícil assumir... é difícil assumir porque é um constrangimento. Tu lida com pessoas. Como é que tu vais dizer que estás com depressão ou com TOC?.

No que diz respeito à fuga, ela diz:

Às vezes tu não deseja estar naquela instituição. É a dor de cabeça, é uma dor de estômago, é uma reação do organismo de doença, de doença que de repente não consegue detectar ou que consegue, mas até porque tu não podes demonstrar. Eu tive alguns anos atrás: Tu tens o teu compromisso, sabes que aqui é o teu trabalho, mas quando tu pensas em tudo o que vais encontrar... Me dei conta que tinha que me deparar com aquela turma que era tremendamente angustiante.

Quando inquirida sobre estarem ou não adoecidos os professores da Escola - lócus desta pesquisa, a Professora $\mathrm{C}$ responde com determinação, alinhando ao que Esteve defende como aquilo que o mal-estar na docência implica: Sim. Acho que é por falta de prestígio que hoje o magistério não dá. Há 30 anos atrás eu era uma celebridade, uma pessoa de destaque no meio social. Hoje, não. Hoje é motivo de piada por sermos professores. O autor associa ao desprestígio, a insatisfação, os desenvestimentos, a desresponsabilização, a ansiedade, o estresse, a neurose e a depressão. Entretanto, 
tanto a Professora A como a C, por ora, sentem-se prestigiadas pelos seus alunos, enaltecendo o bom convívio, fortalecendo o gosto pela profissão.

\section{A potência da escrita e da leitura}

O que pode uma escrita e uma leitura? - perguntaria Spinoza (2002). Nunca se chegará a uma resposta exata sobre o processo de escrileiturar. Apenas o que se pretende é focalizar a potência do ler e do escrever e vice-versa como exercício clínico no empreendimento da saúde em detrimento do mal-estar docente. Todavia, faz-se necessário ampliar a compreensão de clínica desde a Psicologia Institucional, considerando os estudos de Guattari (2004), Guattari; Rolnik (1999) e Gilles Deleuze (2011).

Nesse sentido, a transversalidade dos saberes é destaque, tendo na trama dos elementos da arte, da filosofia e da ciência, território consistente para as tentativas de expressão frente ao adoecimento dos sujeitos pertencentes a esta contemporaneidade - no caso desta pesquisa, dos docentes da rede estadual de ensino da cidade de Rio Grande. Na direção adotada, notável é parte do depoimento do Professor B, favorecendo esse argumento ao afirmar:

A gente percebe que narrativas alternativas fora do espaço acadêmico e fora do espaço escolar vêm surtindo efeito, muito mais efeito na construção das sociedades e das culturas [...]. Então, a gente nota que as letras de músicas, as narrativas das novelas, as narrativas do cinema, as próprias narrativas das comunidades, elas acabam surtindo mais efeitos na construção das culturas sociais, do que a própria escola e do que a própria universidade.

Na visão deleuziana, a clínica não obedece ao tempo organizado, estratificado, pois não haveria um passado a descobrir, mas a inventar segundo o dobramento a que estará submetido e que o irá situar num feixe de relações insuspeitado. Trata-se, então, de propor uma escuta apoiada no pensamento da diferença, no qual a noção de subjetividade é reformulada, tal qual defendida por Guattari como

O conjunto das condições que torna possível que instâncias individuais e/ou coletivas estejam em posição de emergir como território existencial auto-referencial, em adjacência ou em relação de delimitação com uma alteridade ela mesma subjetiva. (GUATTARI, 2012, p.19).

Assim, justifica-se o arranjo de autores literários tais como Kafka, Manoel de Barros e Cortazar, bem como ideias dos filósofos Deleuze, Nietzsche e Spinoza. Em Crítica e 
clínica, afirma Deleuze (2011) que a literatura ou a escrita "[...] aparece, então, como um empreendimento de saúde" (p.13-14). O filósofo indica a saúde como literatura, como escrita na atitude que consiste em inventar um povo que falta. Isto é, ao ler e escrever materiais potentes para fomentar o pensamento, são acionados estados de existência em variação "quando invoca essa raça bastarda oprimida que não para de agitar-se sob as dominações, de resistir a tudo o que esmaga e aprisiona e de, como processo, abrir um sulco para si" (DELEUZE, 2011, p.15).

O procedimento de agenciar convoca possibilidades diferentes de produzir pensamento e escrileituras. Com a arte é possível ver, ouvir e sentir. O que reverbera a necessidade de criar com arte? A emergência de expandir um desejo a conduzir blocos de sensações em quem os experimenta. Já a Filosofia cria conceitos. Isso auxilia na produção de imagens de pensamento em relação àquilo que se quer escrever: uma poesia, uma música, uma estória, etc. Eles são produzidos a partir de um plano de imanência, local onde se recolhem os elementos desse plano e o seu arranjo produz o conceito. A filosofia trata de orientar o pensamento a enfrentar os problemas construídos. Assim, o conceito se refere a um acontecimento no pensamento que é mobilizado por aquilo que inquieta. $\mathrm{Na}$ Ciência, são criados os functivos, que tratam da relação entre limite e variável, são as funções que conduzem à desaceleração do caos (DELEUZE; GUATTARI, 1996).

Tendo em vista tal intenção em agenciar elementos diversificados para produção de escrileituras, é benevolente pensar naquilo que serve de material para a coisa escrita: Tudo que possui força para acionar o pensamento, serve! "Tudo aquilo que nos leva a coisa nenhuma, dejetos e coisinhas sem importância, enfim, todas as coisas jogadas fora podem convergir para o mesmo ponto, o ponto inicial da escrita" (COSTA, 2010, p. 9).

\section{Ateliês de escrileituras: Isso funciona?}

Ao término dos dois Ateliês, pediu-se aos participantes que respondessem à questão: Isso funciona? Também foi retomada essa pergunta durante a entrevista, na busca da produção de sentidos para a intervenção proposta. Não como cura ou medida paliativa diante do mal-estar docente, mas como dispositivo ativador da potência de vida, através do traçado transversal da filosofia e da arte.

As filosofias da diferença e as práticas estéticas atuais têm demonstrado uma enorme capacidade de contribuição para problematizar os processos de subjetivação docentes, mediante as transformações sociais. As discussões conceituais e os modos de fazer que esses campos põem em jogo, atualmente, têm muito a auxiliar nos estudos sobre como alguém se torna professor, com vistas a: superar o entendimento do campo da arte como disciplina, abordando-o como potência de criação; superar a identificação do 
campo filosófico com discursos herméticos de especialistas, para aprender com suas formas de problematizar a realidade e produzir diferença.

Nessa direção, a professora A respondeu:

No primeiro ateliê, o nosso grupo não estava preparado para aquela atividade, porque trabalhar com Filosofia é difícil, a gente trabalhar com Filosofia... Assim... É engraçado. Primeiro porque de alguma forma mexeu comigo, daí eu comecei a anotar e anotar. [...] Então, de alguma forma aquilo mexeu comigo, me produziu um sentimento, me provocou, mas é claro que eu não pude ficar até o fim.

Os Ateliês de Escrileituras favorecem outras maneiras de pensar, melhor dizendo, pensar-se. Uma intervenção que destitui as habilidades que um professor deve atingir, previamente definidas como uma identidade a ser alcançada, possibilitando a construção de critérios de existência para uma vida que também é docente, mas não somente docente.

Por meio dos Ateliês que, em seus procedimentos de leitura-e-escrita, implicam o campo do vivido, dos sentidos, das sensações e das invenções; solicitam um tempo que não é o cronológico, mas o da duração; autorizam-se a fazer atravessamentos na ortodoxia dos textos, para existir a seu modo; reivindicam outras maneiras possíveis de inscrever signos e de escriturar sentidos.

Considerando que "a vida deve ser traduzida, como processo de criação" (VILLANI, 1999, p.71), nesses circuitos e transcursos tradutórios, os Ateliês privilegiam elementos de funções científicas, de conceitos filosóficos, de perceptos e afectos artísticos, extraídos de obras já realizadas, que outros autores criaram, em outros planos, tempos, espaços, línguas, como as suas efetivas condições de possibilidade, necessárias para a própria execução; e, ao mesmo tempo, como o seu privilegiado campo de experimentação, necessário para as próprias criações de leitura-e-escrita. Com esses elementos originais, constitui um campo de variações múltiplas e disjunções inclusivas, que compõe linhas de vida e devires reais, promove fugas ativas e desterritorializações afirmativas de uma vida potente: eu posso me expor, eu posso brincar, eu posso cantar, eu sou desengonçada. Certo! Eu posso ser mais autêntica, garante a Professora C sobre o segundo Ateliê, que possui caráter lúdico de revigoração de um estado crianceiro na vida cotidiana.

Quanto ao Ateliê Conatus, é relevante rememorar que se teve como intenção a produção de uma novela de rádio como produto dos trabalhos desenvolvidos. Talvez seja interessante falar sobre a primeira vez em que se escutou um dos áudios. Teve-se uma forte sensação de violência. Inicialmente, sendo acometida pelo coro das Mulheres mugindo como fundo musical, comandadas pela voz do homem ocidental da 
modernidade, nomeando todo um coletivo docente como VACA professoral. Era isso o possível de ser escutado:

Na Índia a vaca é um animal sagrado, não pode ser morta ou molestada. No Brasil não poderia ser diferente, claro que de um modo bem Tupiniquim: aquela vaca me rodou (muuuuuuuuuuuuu), a vaca me botou na rua (muuuuuuuuuuuuu), a vaca de física me deixou em exame (muuuuuuuuuuuuu), pô a vaca de história não me deu dois décimos (muuuuuuuuuuuuu), a porcaria da vaca não me deixou entrar (muuuuuuuuuuuuu) [...]. Ao ouvir os sábios conselhos o inimigo das vacas esbaforido com os próprios pensamentos que se transformavam em outros pensamentos, pesado e cheio de teia concluiu: - Eu vou arremessar o sinalizador naquela vaca (muuuuuuuuuuuu). E como estamos em um mundo machista quem não é vaca é viado. Não você está enganado, não estamos no campo, bem vindo às escolas brasileiras (muuuuuuuuuuuuu) (Podcast intitulado $\mathrm{A}$ vaca).

Ali se pode escutar uma escritura de um mal-estar docente que diz do como sou nomeado, das forças que sou acometido ou fortalecido no dia a dia da prática da profissão, considerando um dado contexto escolar nesta contemporaneidade. Passou-se, enfim, a habitar um território que até então não existia, com a cautela necessária a quem lida com o desconhecido. Explorá-lo através dos olhares, das escutas, da sensibilidade, da percepção de cada movimento. E, a cada novo dia, novos afetos se constatarem naquilo que a todos afetava (NASCIMENTO; PINTO, 2013).

Ora, se, por um lado, posso pensar a escrileitura como um problema relativo a uma dada fórmula ou modelo prévio, por outro, posso pensar a escrileitura como um problema ao modo deleuziano. Para o filósofo, um problema é colocado quando há uma abertura inabitual sobre o mais familiar. Há um novo corte no caos, a invenção de um plano de pensamento. Um problema é construído quando existem necessidades para sua existência.

Uma pesquisa, uma escrileitura, uma pesquisa em escrileituras dizendo do mal-estar que habita em meio à vida professoral, que menos coloca o professor no lugar de construtor de um Brasil melhor, abrigando esse fardo incomensurável. Ou que coloca em um lugar de menor valia diante das categorias laborais. Ficam as questões: Que mal-estar é esse? Que doença é essa? O que aqui ainda se pode dizer? Está o professor de fato adoentado? Não há respostas diretas, objetivas e totalizadoras para tais questões.

\section{Achados e perdidos de uma cartografia}

Aí está: "não fui muito longe, mas já era um começo" (DELEUZE, 2013, p.15-16). Talvez apenas um movimento inicial que tenta ativar o mal-estar docente. De algum modo 
diverso das concepções que o amarram fortemente à clareza, coerência, concisão, atividade científica denotativa e à representação do aprendido. Uma ação que não pretende apenas discorrer sobre causas e consequências do adoecer professoral, tampouco enunciar os significados da doença, nem oficializar seus procedimentos.

Nessa perspectiva, foi possível realizar esta experimentação. Operar um método que permite perceber o processo de fazimento e desfazimento do território habitado, em que a leitura e a escrita são ferramentas infinitamente potentes: Fazer subir diferentes planos à superfície, traçar percursos como saúde que cada escritura implica, propõe ou vê frustrado. Uma cartografia cuja tarefa consiste em marcar caminhos, assinalar os muros que impedem o movimento e obstruem a saída, de modo a encontrar suas linhas de fuga.

Com alguma clareza, indica que o trabalho intervencionista com Ateliês de Escrileituras demonstrou outra forma de realizar clínica, distante do modelo individualista herdado da Medicina, mais próxima da maneira Social e Institucional, propositoras de intervenções crianceiras que apostam na liberação da potência vital (conatus). Lá onde o indivíduo se encontra submetido ao controle dos modos menores de existir. Tal clínica pode fazer da experiência, dos encontros e da criação, algo mais que uma ação pessoal ao pôr em jogo a forma de expressão mesma da experimentação.

Então, destacam-se os Ateliês enquanto uma tentativa multi e transdisciplinar para colocar a ler e escrever a partir de conexões de diversas áreas de saberes: arte, ciência e filosofia. Com isso, procura-se arejar os estratos e as representações do pensamento do senso comum que impõem ao professorado uma condição de funcionamento pautado na doença em função da exigência das mesmas condutas, do ensinar os mesmos conteúdos, do perguntar as mesmas perguntas e formular as mesmas soluções a muitas gerações de alunos. Outros modos possíveis de realizar a docência: Suspender velhos hábitos, deixar de lado aquilo que não eleva uma potência de vida, ativar forte disposição para capturar e agenciar materiais distintos que possibilitem multiplicar-se na variação daquilo que é reunido.

Por ora, a cartógrafa pode dizer que as atividades grupais de leituras e escritas são dispositivos de produção de subjetividades. Trazem a riqueza de um processo de construção de novas formas de convívio consigo, gerando e fomentando uma relação mais saudável com suas dores vitais, contrapondo-se a serenidade da mortificação do ato de criação presente no ser professor.

Ela também necessita salientar um novo entendimento sobre o trabalho dos experts educacionais, que se colocam a serviço das entidades e das forças que são dominantes em nossa sociedade. São eles que acabam por prescrever identidades professorais, despossuindo a categoria de um saber acumulado durante anos de experiência vital, 
sendo esse saber relegado, colocado em um segundo plano. Com tantas indicações sobre como ser e fazer ao modo de uma demanda modulada por tais experts, acaba-se por perder o controle sobre as próprias condições de vida, ficando-se alheio ao poder de gerenciar a existência, aconchegando-se em determinações que indicam que a educação está doente.

"Uma saída, apenas uma saída", grita o macaco de Kafka (1999, p.62). Por ora, uma tentativa de atuar como formadora de professores, catalisadora de processos autoanalíticos, conforme indica o Institucionalismo. O que isso quer dizer? Consiste em possibilitar aos coletivos professorais atuarem como protagonistas dos seus problemas, das suas necessidades, das suas demandas, podendo enunciar, compreender, adquirir ou readquirir um vocabulário próprio que lhes permita produzir saberes acerca de sua própria existência, construir critérios de vida na imanência por uma ética docente.

Enfim, a insistência na busca por respostas já soa com desconforto. Nunca se sabe ao certo. Nunca se saberá o que se passou exatamente. Diga lá, diga lá... Algo se solta, se liberta, irrompendo pelas fissuras de alguma estratificação. Uma torrente que não é expressa pela restituição da ordem puramente racional. É pelo acaso das fendas no abandono das palavras mais competentes que o pensamento sobre o mal-estar docente vai silenciando na explosão do indizível, do insensato, do inefável: "Num momento assim, digam o que disseram. De qualquer forma, acho que vou parar" (BECKETT, 2004, p.99).

\section{Referências}

BARTHES, R. Inéditos: v.1 teoria. São Paulo: Martins Fontes, 2004.

BAUMAN, Z. Modernidade líquida. Rio de Janeiro: Zahar, 2003.

BECKETT, S. Malone morre. São Paulo: Códex, 2004.

CORAZZA, S. M. Notas para pensar as Oficinas de Transcriação (OsT). In: HEUSER, E. M. (Org.). Caderno de Notas 1: projeto, notas \& ressonâncias. Cuiabá: UFMT, 2011.

COSTA, L. B. Biografema como estratégia biográfica: escrever uma vida com Nietzsche, Deleuze, Barthes e Henry Miller. Tese (Doutorado em Educação). Programa de PósGraduação em Educação, Faculdade de Educação, Universidade Federal do Rio Grande do Sul. Porto Alegre: UFRGS, 2010.

CORTÁZAR, J. Discurso do urso. São Paulo: Galerinha Record, 2009.

DELEUZE, G. Crítica e clínica. 2.ed. Rio de Janeiro: Editora 34, 2011.

DELEUZE, G. Conversações. São Paulo: Editora 34, 2013.

DELEUZE, G.; GUATTARI, F. O que é a filosofia? Tradução de Bento Prado Jr. e Alberto Alonso Muñoz. Rio de Janeiro: Editora 34, 1996.

Revista Digital do LAV - Santa Maria - vol. 9, n. 2, p. 28 - 44. - mai./ago. 2016 ISSN 1983 - 7348 
DELEUZE, G.; PARNET, C. L' Abécédaire de Gilles Deleuze (Entrevista com Gilles Deleuze). Editoração: Brasil, Ministério de Educação, "TV Escola", Paris: Editions Montparnasse, 2001.

ESTEVE, J. M. Z. O mal-estar docente: a sala de aula e a saúde dos professores. 3.ed. Bauru, SP: Edusc, 1999.

FOUCAULT, M. Nascimento da biopolítica. São Paulo: Martins Fontes, 2008.

FONSECA, T. M. G.; KIRST, P. G. (Orgs.). Cartografias e devires: a construção do presente. Porto Alegre: UFRGS, 2003.

GUATTARI, F.; ROLNIK, S. Micropolítica: cartografias do desejo. 5.ed. Petrópolis, RJ: Vozes, 1999.

GUATTARI, F. Caosmose: um novo paradigma estético. 2.ed. São Paulo: Editora 34, 2012.

GUATTARI, F. Psicanálise e transversalidade: ensaios de análise institucional. Aparecida, SP: Ideias \& Letras, 2004.

KAFKA, F. Um médico rural: pequenas narrativas. São Paulo: Companhia das Letras, 1999.

MÜLLER, D. Cuidado: a saúde da educação está em perigo. Publicação do coletivo estadual de saúde do CPERS/Sindicato, 2012.

NASCIMENTO, J. M. do; PINTO, L. A. Vidas minúsculas: cartografando viveres infantis. In: RODRIGUES, C. G. (Org.). Caderno de notas 5 Oficinas de escrileituras: arte, educação, filosofia Oficinas produzidas em 2011. Pelotas, RS: UFPel, 2013, p.197-206.

PASSOS, E.; KASTRUP, V.; ESCOSSIA, L. da (Orgs.). Pistas do método cartográfico: pesquisa-intervenção e produção de subjetividade. Porto Alegre: Sulina, 2009.

PAULON, S. M.; ROMAGNOLI, R. C. Pesquisa-intervenção e cartografia: melindres e meandros metodológicos. Estudos e Pesquisas em Psicologia, v.1, p.85-102, 2010.

ROLNIK, S. Cartografia sentimental: transformações contemporâneas do desejo. São Paulo: Estação Liberdade, 1989.

ROMAGNOLI, R. C. A cartografia e a relação pesquisa e vida. Psicologia e Sociedade, v.21, n.2, p.166-173, 2009.

SPINOZA, B. de. Ética demonstrada à maneira dos geômetras. São Paulo: Martin Claret, 2002.

VILLANI, A. La guêpe et I'orchidée: essai sur Gilles Deleuze. Paris: Belin, 1999.

1 Professora associada do Departamento de Ensino e docente permanente do PPGE da FaE/UFPel. Doutora (UFRGS) e Mestre em Educação (UFPel). Bacharel em Psicologia (UCPel), Licenciada em Matemática (UCPel). Pesquisadora no Grupo Escrileituras da diferença em Filosofia-educação (CNPQ) e Educação e contemporaneidade: experimentações com arte e filosofia (CNPQ). 
2 Doutoranda do Programa de Pós-Graduação em Educação da Universidade Federal de Pelotas (UFPel). Professora da rede estadual de ensino do Rio Grande do Sul. Endereço eletrônico: josiwikboldt@hotmail.com

Enviado em: 30 de maio de 2016.

Aprovado em: 01 de agosto de 2016.

Revista Digital do LAV - Santa Maria - vol. 9, n. 2, p. 28 - 44. - mai./ago. 2016 ISSN 1983 - 7348

http://dx.doi.org/10.5902/1983734823505 